\title{
Contestation over an island imaginary landscape: the management and maintenance of touristic nature
}

Article

Accepted Version

Kothari, U. and Arnall, A. (2017) Contestation over an island imaginary landscape: the management and maintenance of touristic nature. Environment and Planning A, 49 (5). pp. 980998. ISSN 0308-518X doi:

https://doi.org/10.1177/0308518X16685884 Available at https://centaur.reading.ac.uk/68321/

It is advisable to refer to the publisher's version if you intend to cite from the work. See Guidance on citing.

To link to this article DOI: http://dx.doi.org/10.1177/0308518X16685884

Publisher: Sage

All outputs in CentAUR are protected by Intellectual Property Rights law, including copyright law. Copyright and IPR is retained by the creators or other copyright holders. Terms and conditions for use of this material are defined in the End User Agreement.

www.reading.ac.uk/centaur 
Central Archive at the University of Reading

Reading's research outputs online 


\title{
Contestation over an island imaginary landscape: The management and maintenance of touristic nature
}

\begin{abstract}
This article demonstrates how maintaining high-end tourism in luxury resorts requires recreating a tourist imaginary of pristine, isolated and unpeopled island landscapes, thus necessitating the ceaseless manipulation and management of space. This runs contrary to the belief that tourism industries are exerting an increasingly benign influence on local environments following the emergence of 'sustainable tourism' in recent decades. Rather than preventing further destruction of the 'natural' world, or fostering the reproduction of 'natural' processes, this article argues that the tourist sector actively seeks to alter and manage local environments so as to ensure their continuing attractiveness to the high-paying tourists that seek out idyllic destinations. Additionally, by drawing on an example of tourism development, environmental change and local conflict in the Maldives, it shows how interventions by tourism managers can result in conflict with local people who, possessing different imaginaries, interests and priorities, may have their own, often long-established, uses of the environment undermined in the process. The article concludes that the growing diversity and increasing environmental awareness of tourists is currently producing a range of complexities and ambiguities that preclude any easy and straightforward environmental response by the sector, and ultimately might destabilise the Western-based tourist imaginary itself.
\end{abstract}

\section{Introduction}

The provision of a particular representation of nature as pristine and unpeopled, much sought after by high-end tourists to tropical island resorts, paradoxically requires the ceaseless management and 
maintenance of the natural environment. The vitality that inheres in the non-human world, such as the dynamism of plants, animals and microbes, and the continuous transformation wrought by chemical and biological action, necessitates an endless endeavour to keep nature at bay (Graham and Thrift 2007). Wind blows sand into irregular piles, vegetation sprouts through cracks if left untended and seaweed washes up onto beaches. Thus, the production of a particular tourist imaginary of unspoilt and untouched landscapes requires the ongoing maintenance of non-human nature (Edensor 2001). Furthermore, the tendency is for notions of the natural in the tourist island imaginary to abstract people out of the scene or for only particular kinds of people, carrying out particular tasks, to be allowed entry, for the idea of the natural is often understood as one that does not include humans (Gordon 1997). Accordingly, this illusion, and the tourist desires for a deserted and unpeopled island that it sustains, also requires the incessant management and control of the movement of people into and through the landscape.

This article explores how a tourist imaginary of pristine, isolated and unpeopled island landscapes requires ongoing and attentive management of space, which runs counter to the belief that tourism industries have exerted an increasingly benign influence on local environments following the emergence of 'sustainable tourism' in recent decades. Rather than preventing further destruction of the 'natural' world, or fostering the reproduction of 'natural' processes, the tourist sector can actively seek to alter and manage local environments so as to ensure their continuing attractiveness to the highpaying tourists that seek out idyllic destinations. While forms of tourism are diverse and tourists seek different kinds of experiences, this article focuses primarily on high-end tourism in small tropical islands. As we argue, imaginaries of deserted, paradisal islands are invoked by an industry intent on commodifying landscapes to produce a specific 'touristic nature' that becomes dislocated and abstracted from other natures. Highlighting this multiplicity of natures, this article focuses on how interventions by tourism managers often result in conflict with local people who, possessing different 
imaginaries, interests and priorities, may have their own, often long-established, uses of the environment undermined in the process.

These arguments are illustrated by drawing on an example of tourism development, environmental change and local conflict in the Maldives, a low lying island archipelago located in the Indian Ocean, south of the Indian mainland. Of a total of almost 1200 islands, 200 are inhabited by local communities and 100 are used as resorts. The Maldives is renowned for high end, luxury tourism and has played a significant role in popularising the now widely recognised image of the 'deserted' tropical island since the development of its first international resort in the early 1970s. Tourism development in the Maldives was until recently based on a 'one-island one-resort' policy that ensured exclusivity. Importantly, a policy of only permitting resorts on uninhabited islands provided an illusion of isolation and effectively limited encounters between tourists and locals. However, pressures to allow Maldivians to benefit from the profitable tourist sector has led to the recent introduction of a second tourism development model in which tourists now have the option of staying in cheaper accommodation in locally-owned and run 'guesthouses' on inhabited islands (Zubair et al 2015). This policy shift has led to a more complex and occasionally conflictual relationship between international resort managers, guesthouse owners, local populations and the so-called 'natural' environments on which they all variously depend.

The rest of this paper is structured as follows. The next section engages with the burgeoning sustainable tourism literature to show how the tourist industry has aimed to lessen its impact and influence on the 'natural world' and local populations through the implementation of 'weak' and 'strong' sustainability. Subsequently, in section three, these approaches are contrasted with the need for resort and guesthouse managers to actively intervene to transform and manage nature in order to maintain an idealised representation of a remote, isolated and pristine island landscape to attract visitors. Here, the Maldivian context and case study methodologies are also introduced. Section four provides two 
comparative case studies of tourist development and local conflict in two islands in the south Male atoll: the first is a luxury, international resort on a 'deserted' island; the second is a 'lower end' guesthouse development on an inhabited island.

Using these illustrations, the article shows that a prevailing tourist imaginary of pristine and empty islands requires ongoing maintenance of the environment. This presents a series of challenge to attempts by the tourist industry to adopt a sustainability approach, in particular the potential emergence of conflict with local populations. Moreover, the growing diversity and increasing environmental awareness of tourists is currently producing a range of complexities and ambiguities that preclude any easy and straightforward environmental response by the sector, and ultimately might destabilise the Western-based tourist imaginary itself.

\section{Tourism and sustainability: minimising impact on the natural environment}

Ever since the advent of mass air travel and the arrival of the 'package holiday' in the 1960s, the relationship between tourism and the natural environment has been scrutinised by scientists, policymakers, tourist industries and campaigners (Moranda, 2015). In general, the basis of this scrutiny has been an underlying belief that the development of tourism and the functioning of the natural world are fundamentally at odds with one another due to a wider economic or capitalist logic that subordinates environmental concerns to economic interests (Cohen and Cohen, 2012). Accordingly, over the past few decades, an extensive literature has developed to catalogue the long-term, irreversible and negative effects of tourism on the natural environment that include pollution, the depletion of commons-based resources, such as water and land, and a range of physical impacts such as the trampling of pathways and the damage caused to sea beds by the anchoring of boats 
(Briassoulis, 2002). Moreover, these problems have been viewed as having been compounded by a host of political and institutional practices, such as the capture of natural resources by private, state and international interests, very often at the expense of local populations who have had a host of socioeconomic and public health risks transferred to them (Farrel and Twining-Ward, 2004).

Initial attempts to address these problems occurred during the 1970s and 1980s when scientists developed the idea that different natural habitats possess an innate 'carrying capacity'. This raised awareness of the need to limit human activities to within certain 'safe' limits beyond which irreversible damage to the environment can occur (Hillary et al., 2001). Saarinen (2006) extended this approach by identifying three main ways or 'traditions' in which the limits to growth manifest themselves with regard to the tourism sector (Saarinen, 2006): a resource-based tradition, grounded in positivism and the natural sciences, that seeks to identify a numerical point beyond which serious negative impacts on an available resource will occur; an activity-based tradition, drawing on lifecycle approaches to describe the change process that occurs as a new tourist site is developed from an early exploration to late stagnation stage; and a community-based tradition, which seeks to integrate the interests of local stakeholders and groups into the carrying capacity-based calculation around activities, limits and thresholds.

Although these ideas, and the development of the global 'green' movement that accompanied them, did have some influence over the tourism sector, the basic approach wherein the preservation of the natural world is pitched in an oppositional relationship to the economic activities of tourists came to be conceived as over-simplistic (Briassoulis, 2002). In its place, a new sustainability perspective developed in the 1990s in which tourism industries were no longer viewed as separate from, and acting in opposition to, the natural world. Instead, tourism was increasingly viewed as part of a three-fold, interactive system consisting of economy, environment and society (Farrell and Runyan, 1991). In this 
new 'shared space', the need for economically viable tourism was recognised, alongside the imperative to avoid depletion of the resources upon which the future of the industry depends, notably the physical environment and the social fabric of the host community (Farrell and Twining-Ward, 2004).

According to the sustainability science literature, two main forms of sustainability can be identified (Kousis, 2000): 'weak sustainability', which is often seen as occurring within prevailing patterns of production, consumption and resource exploitation, and thus appealing to the more conservative elements of environmental organisations; and 'strong sustainability', which involves more fundamental shifts in those patterns in favour of environmental protection, social justice and poverty reduction. According to Kousis (2000), weak sustainability is often driven in practice by pragmatic interests concerned with the need to ensure profitability over the medium to long run. The literature on tourism and environment reveals three main dimensions to these interests. First, tourism industries are well aware that tourists often go to destinations to enjoy particular environmental features, and that the quality of these directly shape their enjoyment of a particular place, and whether or not they are likely to return (Uyarra et al., 2005). There is therefore a paradox at the centre of much tourism whereby "the more attractive a site...the more popular it may become, and the more likely it is that it will be degraded due to heavy visitation, which in turn may diminish the quality of the experience" (Mbaiwa and Stronza, 2009; 338). Adopting a sustainable approach is therefore seen as a way of keeping particular holiday destinations popular and therefore profitable.

Second, many tourists are now viewed as increasingly discerning with respect to environmental concerns (Esparon et al., 2015). Thus, in an attempt to differentiate their tourism product or 'experience' from that of their competition and thereby increase the attractiveness of their holidays, many travel companies market the notion of working 'alongside' or in 'partnership' with the natural world. This development is reflected by the increasing tendency for hotels and resorts in ecologically 
sensitive areas, such as the Maldives, to employ conservation scientists and other environmental specialist to assist (and to be seen by tourists as assisting) in the monitoring and preservation of the natural environmental.

Third, avoiding over-exploitation of the natural resource base is understood as a way of avoiding local conflict and protest (Kousis, 2000). According to Nunkoo and Gursoy (2012), whether local residents show support or opposition towards a nearby tourist development is based on their environmental and social identities. There is now a considerable body of literature to demonstrate how destruction of the local natural environment by tourist activities can create considerable animosity amongst affected local populations, and that resistance by these groups can seriously disrupt tourists' activities (Yang et al., 2013).

There is little doubt that the so-called 'weak sustainability' approach has had an effect on the rhetoric, policies and activities of the global tourist industry. However, in spite of these developments, some commentators, such as Holden (2009), have questioned the extent to which the relationship between tourism and the natural environment has actually improved as a result of weak sustainability. Arguably, much more far reaching in its effects has been the implementation of a strong sustainability approach by tourist industries since the 1990s. This movement is reflected by the notion of 'responsible tourism', whereby tourists adopt an ethic of 'leaving no trace', 'impacting lightly' or leaving behind a 'pristine leisure landscape' for others to enjoy (Grimwood et al., 2012). The approach is also associated with the emergence of alternative, more ecologically conscientious forms of holiday, including nature tourism, wildlife tourism, adventure tourism and ecotourism (Farrel and Runyan, 1991). These activities are significant in that they amplify 'the reality of the 'environment' in ways that elevate it from the status of 'setting"' (Kern, 2000: 26) and highlight the importance of paying 'attention to the visual economies associated with this form of tourism' (Carrigan, 2010: 161). Indeed, many such holiday experiences 
might enrol tourists themselves in the protection of the natural world, as evidenced by the proliferation of participatory activities such as turtle or primate monitoring and mangrove restoration. In recent years, these developments in sustainability science have been supplemented by growing interest in the social sciences in concepts of vulnerability and resilience, and in particular the notion that tourist destinations should have resilience built into them in the face of global environmental and economic change (Calgaro et al, 2014; Calgaro and Lloyd, 2008).

To sum up, this section has demonstrated how tourism development and its effects on local ecologies and populations has become of increasing significance and concern. In response, tourist industries in some places have begun to respond to calls to mitigate the adverse effects of the sector on the environment through sustainable tourism initiatives. However, what we argue below is that alongside this emergence of sustainable tourism, with its focus on working in harmony with the non-human world, is the ongoing intensive management of 'nature' required to sustain certain forms of tourism. In particular, maintaining high-end tourism in luxury island resorts requires the recreation of a tourist imaginary of pristine, isolated islands on which the tourist sector in many small island states depends, and is something that guesthouses attempt to replicate. As we discuss later, these approaches are not only at odds with one another, but can also act as sources of conflict with local populations who often have competing priorities in the local environments which are being meticulously managed and manipulated.

\section{Creating and sustaining a tourist island imaginary}

As outlined in the previous section, central to the idea of sustainable tourism is the notion that, somewhere 'out there', there exists a 'natural' or 'pristine' world which is free from the effects of 
humans, but into which some people, as consumers, can enter and enjoy. This idea of an untainted natural world persists despite a long history of critiquing the dichotomy between humans and nature (see Castree, 2001), and despite growing awareness that the 'myth of independent nature... belies both the dense biophysical interconnections between people and nature, and the myriad ways in which natures are endowed with social meanings' (Hinchliffe, 2007: 33). And although in recent years, the idea that all landscapes and environments are managed has been increasingly acknowledged (Goudie, 2013; Grove, 1995), less widely understood is how certain places came to be socially produced and envisaged as sites of pristine, isolated nature (Hennessey, 2011). We suggest here that understanding the production of a very specific tourist imaginary will provide insights into how and why tourist managers in small island resorts continuously and almost obsessively manage their immediate natural environment despite their claims of developing more sustainable tourism that works in conjunction with the dynamics and patterns of the natural world.

As DeLoughrey writes (2007), perceptions of islands as pristine, remote and isolated are not statements of fact that describe the obvious nature of islands, but are themselves myths that must be explained. The representation of an insulated and pristine island getaway articulated in much tourist marketing literature and reflecting an ideal much sought after by high-end tourists has its roots in an historical - and particularly colonial - geographic imaginary of 'islandness' (DeLoughrey, 2007). Islands have long been idealised and imagined as remote and paradisal sites, idyllic places of Edenic nature, providing primitive escapes from modernity (Slater, 1996). For Said (1979), this geographic imaginary literally refers to how spaces are 'imagined', how meaning is ascribed to physical spaces, how knowledge about these places is produced, and how these representations enable particular activities and interventions to take place within them (Kothari and Wilkinson, 2010). There are thus resonances between certain forms of contemporary tourism and the construction of particular spaces that reveal the legacies of colonialism manifest in tourist practices (Osagie and Buzinde, 2011). Thus, as Lynch 
(2011:1) reminds us, 'the natural environment, as much as the human cultures which inhabit it, are subject to the effects of colonisation and its lingering and pernicious legacies'.

Despite recent attempts to unsettle these representations and assumptions (see Stratford et al, 2011), they endure. This is, in part, because the persistence of notions of pristine, untouched touristic nature require the resort locations themselves to modify their 'natural' world in order to comply with these imaginaries and fulfil the expectations of high-paying tourists. Islands have often been considered ideally suited to the task of 'managing nature', being small and therefore more easily controllable (Grove, 1995; DeLoughrey, 2007; Baldacchino 2007). This specific kind of management may conform to the normative imaginary but in so doing produces an artificial state in which, for example, beaches are constantly swept and raked to give the illusion of an untouched environment, and sand is dredged to produce shallow lagoons of clear blue water. This ongoing complex procedure to control, repair and maintain the material world and the incessant rhythms of cleaning and inspection provides a powerful illusion of durability (Edensor 2016). This continuous reordering of matter and space is performed by an army of resort staff, often working during the night or early morning, to sweep away the debris and dirt of the day, and these activities are crucial to ensuring that the tourist imaginary is sustained. In this sense, such labour seems to characterise 'the things and the people who are primarily unseen and banished to the periphery of our social graciousness' (Gordon, 1997: 196). In addition, maintenance and repair sustain the illusion that the world is 'characterized by perfect order, completeness, immanence and internal homogeneity rather than leaky, partial and heterogeneous entities' (Graham and Thrift, 2007: 10).

Resorts are thus constructed as purified spaces, reflecting a particular version of the local environment (Edensor and Kothari 2003). What tourists see is an essentialised view of the natural landscape, one that is understood to be timeless and unchanging. In order for them to imagine themselves as 
castaways, albeit with luxuries and high-quality services, nature has to be continuously and carefully managed and manicured. This particular vision of islandness is reproduced in travel writings and tourist brochures, invoked by a tourist industry intent on commodifying the landscape. The process of attempting to produce and maintain this distinct version of nature (see Cronon, 1996) necessarily increases the likelihood of conflicts emerging between different versions of, and aspirations for, other natures.

\section{Tourism development in the Maldives}

This article focuses on how the Maldives, in an attempt to establish itself as an attractive tourist destination, has adopted the approach of sustainability whilst also drawing upon a colonial geographical imaginary to rework the image of an isolated, untouched and remote paradise, and to commodify a deserted island aesthetic. The examination of specific forms of contestation over representations and uses of the environment that result requires an understanding of the history and significance of tourism in the country. The Maldives consists of 1192 islands covering a total of 298 square kilometres. Its population of approximately 380,000 people inhabits only 192 of these islands and Malé, the country's capital, is extremely densely populated, with 120,000 people living in approximately six square kilometres. The country is classified by the UN as a lower middle-income country, although $16 \%$ of the population lives below the poverty line and unemployment is at $28 \%$. Its economy, which is heavily dependent on tourism (accounting for almost $30 \%$ of GNP) (UNDP, 2014), plays an important role in earning foreign exchange revenues and generating employment in the tertiary sectors of the country.

The Maldives is internationally recognised as a prime location for high-end luxury island tourism. The first resort in the country opened in 1972 and in 2013 this had grown to almost 130 establishments 
(Maldives DoT, 2013). In recent years, another 70 undeveloped leases have been allocated to international companies looking to expand their operations in the country. Tourist arrivals have maintained a steady growth rate of around $10 \%$ over the last five years, and the Maldives now receives over one million tourists per year. The tourist sector has traditionally targeted the high-end spectrum of the market, adopting a 'one-island one-resort' style of development, with the majority of its visitors (approximately $80 \%$ ) originating from Europe. Since 2009, however, legislation was introduced that allowed for the development of smaller 'guesthouses' on inhabited islands, mostly owned by Maldivian entrepreneurs. This is a significant, if somewhat controversial, policy development as it represents a major break from the traditional model of separating tourists from local populations. The rationale behind the new initiative is to allow Maldivians to directly participate in and thereby benefit from the tourism sector, as well as offering visitors the opportunity to experience 'local' Maldivian culture. There is also a perception that, with increasing numbers of tourists arriving from countries outside Europe, such as Russia, China and India, guesthouses are better suited to the needs of some lower-income families from these countries, in addition to those visiting the traditional four and five star establishments.

It is well known by the country's tourism sector that the 'natural beauty' of the Maldives is the main motivator for visits, with $48 \%$ of tourists stating this to be the case in a recent visitor survey published in February 2015 by the Ministry of Tourism (MoT, 2015). However, it is also widely recognised that the country faces a succession of serious environmental challenges, including waste disposal, water use, biodiversity protection and energy management, most infamously epitomised by the artificial 'rubbish island' of Thilafushi which was constructed in the early 1990s. Over the past few years, the government, via the national Environmental Protection Agency (EPA), and resort companies, have responded to these challenges through a series of coordinated interventions designed, for example, to improve the waste management practices of local communities, develop and enforce management 
plans for environments deemed as 'sensitive', and establish marine reserves in the 'house reefs' of resorts (MTAC, 2013). Arguably, the best known initiative is the Green Tourism Award that was introduced nationally in 1997. The Award aims to make the tourism sector of the Maldives environmentally sustainable by 'encouraging tourism operators and facilities to adopt policies and regulations, as well as eco-friendly strategies, to sustain the environmental integrity and quality of the Maldivian nature, through the inception, performance, implementation and maintenance of environmentally sound practices in tourist operations' (unpublished Green Award guidance documentation, 2015).

The above initiatives are based on a perceived imperative to preserve the 'natural beauty' of the Maldivian environment to the greatest extent possible. However, at the same time, the manipulation and management of that environment to create a particular state of 'pristine' nature for tourists to enjoy is also integral to the country's continuing success in attracting high-paying tourists. Although this 'touristic nature' is difficult to maintain, it is made easier in the Maldives with the 'one-island, one-resort' policy. Major interventions, such as dredging to produce lagoons or shifting sand from one part of the island to another, can be concealed from view and hidden from tourists, and often take place in the offseason, producing an ongoing and seamless social production of nature. Beaches are swept early in the morning before tourists have risen for the day, and regular spraying of the island habitats occurs at night to minimise populations of mosquitos. Moreover, critical physical infrastructure such as diesel power generators, water purifiers and waste management facilities are carefully located out of sight and sound of paying visitors, as are the compounds where resort staff are housed. As we show below, this relentless process of creating and maintaining a particular version of nature and ensuring that a sense of remoteness prevails has consequences for local populations whose environmental management strategies are at times not just different but also in conflict with those of resort and guesthouse managers. 
This article is based on research carried out in July-August 2013 and September 2014 on Malé and Guraidhoo islands. Guraidhoo is located in the south Malé atoll, approximately 30 minutes by speedboat and two hours by ferry from the national capital. The island has a population of approximately 1700 people and its economy is dominated by the nearby Kandooma holiday resort which employs many young people from its population. In Malé and Guraidhoo, a total of 74 semistructured interviews were undertaken to allow in-depth discussion lasting approximately one hour per meeting. A wide range of individuals were interviewed, including government officials $(n=21)$ members of the Maldivian business community (3), tourism managers (6), international tourists (7), resort employees (5), representatives of international organisations (9) and national-level NGOS (5), and 'local' islanders Maldivians (18), who mainly worked as resort employees, small business owners or in the fishing industry. The main topics discussed were national and island-based economic development, environmental challenges and protection, and perceptions of the tourism sector and associated conflicts as well as conflict resolution. During discussions, an interview guide was used to ensure that all topics of interest were covered but also to allow flexibility to explore other new issues if raised by interviewees.

Prior to commencement of the research, all fieldwork was approved by the ethics management committees of the authors' respective universities, and the guidelines and standards set were adhered to throughout the course of the project. The authors already have established contacts in the Maldives through their previous research and a snowballing strategy was used to recruit interviewees for this project and other contacts were identified through government officials from the Ministry of Energy and Environment (MEE). Approximately half of the interviews carried out were recorded using a Dictaphone and were later transcribed, with the remaining half being logged in handwritten note format during the course of the interview. In addition, the researchers attended a number of policymaking events 
including a Tourism Adaptation Project (TAP) meeting in August 2013 at which the Maldivian President spoke and the Green Tourism management workshop in September 2014 organised by the Ministry of Tourism. A range of policy documents about economic growth and tourism development were also examined. These were either public sources accessed via the internet, such as Tourism Master Plans, or policy documents provided to us by key informants. The research was concluded with a one-day workshop in September 2014 to feed back the main research findings to a diverse group of those interviewed. This was undertaken to share more widely the main themes and ideas emerging from the research, as well as to check and verify the researchers' interpretations of the data with other stakeholders.

The qualitative interview data were analysed by reading and re-reading the transcripts numerous time. As this was done, categories of phrases were identified, and theoretical memos were written to track conceptual decisions and ideas about the data as they emerged (Kitchin and Tate, 2000). This process ended when 'saturation point' was reached: when learning and fresh insights became minimal as the same phenomena were uncovered again and again (Bailey et al, 1999). At this point, it was possible to develop preliminary interpretations that explained the situation on the ground, and provided the best 'fit' within the data. Thus the quotations provided in the text that follows are intended to illustrate the range of positions taken by different stakeholders in order to enrich the argument being made, rather than necessarily be representative of the wider population. In this way, the case studies presented below draw on the insights generated to demonstrate how the management and maintenance of touristic nature has created tensions and conflicts with local populations.

\section{Managing environments, creating conflicts}


As Massey (2005) writes, the ways we conceptualise space and nature have profound material effects, and given that particular ways of seeing nature, for example, as pristine and paradisal, is always political (Cronon, 1996; Whatmore, 2002), managing the environment in the ways described above is not without conflict. These conflicts, about which tourists are often unaware, include those over the kinds of alterations that are made to the environment and those over the uneven distribution of the benefits from tourism.

In this section, we provide two illustrative case studies of how the practice of maintaining the imaginary 'natural' state of touristed island landscapes can precipitate conflict by inflaming social inequalities and relations and by bringing new agents with competing interests into the tourist space (see Azcárate, 2010). The first case study shows how maintaining the illusion of isolation requires the creation of places and spaces unpeopled by local Maldivians. However, the geographical proximity of some resort islands to inhabited islands provides challenges to how this image of remoteness, as well as the production of a pristine environment, can be maintained. The second case study has emerged as a consequence of the recently introduced government policy of allowing the establishment of guesthouses on inhabited islands. This has brought together multiple and competing economic interests resulting in tensions that are often played out through a discourse and politics of environmental management.

\section{Conflicts in maintaining the illusion}

While the exclusionary space of most enclavic resort hotels require processes of maintenance through which boundaries are preserved and disorder kept at bay (see Edensor, 2001), in the Maldives the physical separation of tourists from locals is managed through maintaining a geographical detachment and distance between resort islands and inhabited islands. As one NGO official noted, 'The Maldives is really two groups of islands, those that act as tourist resorts and are populated almost entirely by 
tourists and resort staff, and those that are home to ordinary Maldivians'. The production of physical isolation is important to reinforce the illusion of remoteness and separateness, often conceived as a symbol of luxury. This requires not only managing the natural world, but also preventing the unwanted intrusion of local people. Particular members of local populations, such as employees, are only permitted to enter this touristic space in certain conditional and controlled ways: for example, during early morning shift patterns and whilst wearing particular uniforms or costumes which fit with the tourist imaginary.

These distinctions between outsiders and insiders that resonate with colonial spatial divisions are more easily maintained for those in relatively more distant island locations. However, the 'no shoes, no news' high end model of tourism in the Maldives is harder to create where resorts and inhabited islands are in close proximity. For those resorts located near to inhabited islands, maintaining an idealised, pristine natural world is more difficult and increases the potential for conflict, as has been evident in the growing escalation of tensions between Kandooma and Guraidhoo.

Kandooma, a luxury island resort that, according to a recent publicity brochure, invites tourists to 'discover your tropical island paradise', is located 30-40 meters from Guraidhoo, an inhabited island in the southern area of the Malé atoll. Kandooma is reached by speed boat, a 40 minute journey from Male airport. Tourists are met and greeted at the end of the pier before being escorted to the bright and airy reception area. The resort is spread out across the island replete with palm trees, white sand and white and turquoise buildings that merge with the sand and sea. Attention has been paid to the architectural detail and furnishings which extend throughout the resort of 160 single story beach villas identically decorated. The paths that lead from the central reception area to the villas are immaculately maintained, the vegetation manicured and the pool area continuously swept and cleaned so that no matter is out of place. Like many other resort islands, the beaches on Kandooma are regularly raked 
and cleared to produce the paradisal idyll. This work involves not simply removing rubbish, but also sweeping away footprints to create the idea of virgin territory, untouched before the arrival of the tourist. Leaves, twigs and other debris washed up by the ocean are also removed to keep the environment 'neat and tidy'. Twice a day, a small boat ferries employees from and back to their homes on Guraidhoo. Other staff, who live on more distant islands and therefore must live on Kandooma while working, are housed in living quarters that are carefully located out of sight of tourists. Referring to the resort on Kandooma, one non-Maldivian resort worker said, 'The island may be paradise but it takes a lot of grooming. Every day there are work crews taking care of the excess leaves, pruning, raking, sweeping and cleaning the beach'.

Over the past few years there has been an ongoing and at times embittered conflict between the resort and Guraidhoo's island council and resident population. This has arisen due to Kandooma's attempts to recreate an illusion of luxurious isolation, or what is often referred to in the tourist industry as the 'Robinson Crusoe' effect, through the unpeopling of the local environment. Initially, the two islands were connected by a sand bank, and tourists and locals could walk freely between them. However, the resort management argued that Maldivian inhabitants were crossing over from Guraidhoo and stealing from the resort. Importantly, tourists' illusions of an isolated island paradise were being periodically disrupted, not only as Guraidhoo residents wandered back and forth over the sand bank but when, looking up from their beach beds, high-paying tourists could see islanders going about their everyday business a few meters away. So the hotel, to destroy this 'bridge' and further create the sense of disconnectedness from people amongst tourists, dug up the sand bank, thus enlarging the lagoon and effectively separating the hotel from the inhabited island and the tourists from the locals.

The inhabitants of Guraidhoo were angered by the sand mining and dredging because they perceived that these interventions had caused problems of erosion and loss of the shoreline on the eastern and 
south-eastern sides of their island. These effects, they argued, risked damaging houses and infrastructure, and placed more pressures on the already limited amount of space that they had available to accommodate their growing population. In retaliation, as they were no longer able to walk across Kandooma, local inhabitants began to throw household rubbish such as tins, plastic containers and food waste into the sea. This rubbish subsequently washed up on the shores of the resort, leading to the need for more frequent maintenance and cleaning of the beach by the resort.

Insert photo 1 Looking across to Kandooma tourist resort from Guraidhoo island

The President of Guraidhoo Island Council explained the situation when he said,

'The higher erosion [of the Guraidhoo shoreline] is due to the actions of Kandooma. The island asked for help from Kandooma and for them to stop taking sand from the lagoon...But when they [Kandooma] didn't stop, Guraidhoo started to put their trash in the sea which floated over to purposefully antagonize Kandooma.'

The arrival of extra rubbish on Kandooma's beach clearly constituted an additional disruption to the illusion of isolation and pristineness in which the resort has invested considerable financial input to create. As a solution to this problem, the resort funded and built a waste incinerator on Guraidhoo, couching this gift in the spirit of generosity and invoking the language of corporate social responsibility and community engagement. As the manager of the resort explained,

'We have a responsibility to the local people, to support their development. So one of the things we did was to help them with dealing with their waste which is a big problem in the Maldives. We gave the 
local council funds for an incinerator. It's important to us, we have a commitment to supporting the local community'.

However, this attempt to stop local islanders spoiling the image of a pristine ocean and beach backfired when foul-smelling smoke from the incinerator began to drift over from the inhabited island and deluge the resort. As one Guraidhoo inhabitant said, 'Without help from the resort, Guraidhoo had no way to dispose of any packaging from food stuffs to household cleaners. Of course this is burned, sending toxic smoke across Guraidhoo and over the luxury water villas on Kandooma'.

What these incidents show is that, by focusing on their primary economic interests, and by attempting to reproduce the imaginary of an unpeopled and pristine landscape devoid of local inhabitants, Kandooma resort entered into a protracted conflict with Guraidhoo's resident community. While the resort had the resources to manage its immediate environment to establish the tourist imaginary, Kandooma had limited control over local community actions to disenchant the resort's representation of paradise. Ultimately, as Kandooma attempted to create and maintain its state of separateness through its intervention in and alteration of the local landscape, Guraidhoo's residents found other ways of impinging upon the resort through the media of unsightly refuse and malodorous smoke. Thus, ultimately, the inhabited island community had some 'success' in disrupting the tourist imaginary. However, the conflict has also had livelihood consequences for Guraidhoo's population. While resorts are required to source $30 \%$ of their staff from local islands, one interviewee from Guraidhoo explained that the resort had started to employ less staff from their island since the conflict with the resort had begun. Instead, Kandooma had begun to employ more inhabitants from Maafushi, an island located about five kilometres northeast of Guraidhoo, and the focus of the second case study in this article. Although ferrying staff to and from this relatively distant source was more costly for the resort, the measure can be viewed as an attempt by Kandooma to re-establish control by engaging with a local 
population which is more geographically distant and thus ensure the maintenance of its tourist imaginary.

Conflictual environmental and economic interests

According to the Maldivian Ministry of Tourism update in 2015, there are 261 locally-owned guesthouses on inhabited islands in the Maldives providing nearly 4000 beds to tourists, making an average of approximately 15 beds per establishment. For logistical and economic reasons, most guesthouses are located in or near the Malé atoll, with around 40 guesthouses located in the capital city itself. During interviews, it was consistently explained that the main draw of guesthouses for visitors is that they provide a more economical way of seeing the 'natural beauty' of the Maldives compared to the more expensive international resorts.

Insert photo 2 Guraidhoo island guesthouses

As one official at the Ministry of Energy and Environment explained:

'Tourists who visit guesthouses expect poorer facilities and accommodation. They know that drinking [alcohol] is not allowed, that there will be no DJ. However, they also know that they will see a nice beach and the same nice waters to swim in...So they think, 'next time I will visit the guesthouses as well'. They think, 'why should I pay a lot to stay in a resort when I can get the same thing [i.e. the beach and sea] on the inhabited island as well'.

There was a difference in opinion evident amongst MEE interviewees over whether guesthouses are more or less 'green' in comparison to the larger, more luxurious resorts. Some claimed that the kind of 
'low-end' tourists from outside Western Europe or North America that mostly visit guesthouses are less environmentally conscious. Others argued, however, that guesthouses owners are more 'in tune' or 'closer' to their local environment and therefore more likely to protect it. Whichever interpretation might be the case, many interviewees stated that waste management on inhabited islands is more difficult than on resort islands due to the relatively low levels of infrastructure investment in the former. This proved a particular challenge for guesthouse owners; even though the tourists who visit guesthouses may be less interested in isolated luxury and are usually keener to experience cultural encounters, they still want to be immersed within the pristine version of the natural world that they expect in the Maldives and can be upset and disappointed by the presence of pollution or rubbish.

Maafushi Island has a population of about 2000 people. There are approximately 25 guesthouses located on the island, most of which are positioned on its northern side where the best beaches are situated. Together, the guesthouses provide approximately 250 beds for tourists and during the peak season from November to March there can be up to 500 guests, mostly from Eastern Europe, staying on the island. The standard of accommodation in the guesthouses varies from very basic up to a reasonable level of luxury approaching that of international resorts. Maafushi is widely considered to be a 'market leader' in the integration of guesthouses into the physical, social and environmental settings of inhabited islands. This is partly made possible by the island's relatively advanced sanitation and water systems which were newly-installed following the 2004 tsunami. The guesthouse industry on Maafushi also benefits from its proximity to Malé and is thus within reach of the capital city's more educated, entrepreneurial population which can provide the business skills and finance necessary for new business ventures. It was on Maafushi where the first guesthouse in the Maldives, called the 'White Shell', opened in 2010 following the passing of the new legislation in 2009. The White Shell has 22 rooms and is located close to a beach on the northern side of the island. Standard rooms at the 
White Shell cost around US $\$ 120$ each during the high season, and occupancy rates vary from 50 to $100 \%$ over the course of the year.

Despite Maafushi's relatively advanced physical infrastructure, the sudden surge in guesthouse numbers from zero to 25 over the course of five years has presented problems in waste management for guesthouse owners and the local island council. As one guesthouse manager explained, following the arrival of paying guests en masse to the island, maintaining the natural environment has become "the biggest challenge for us...[Our guests] complain if our island is not kept clean. We are forced to keep it clean and we are forced to deal with the garbage in a more than friendly manner". However, problems were clearly arising on other parts of the island that guests were exposed to. For example, one guest stated on TripAdvisor following their holiday that, whilst the beach on the northern side of the island is kept scrupulously clean, 'the other sandy beaches are absolutely filthy which is so sad to see and difficult to describe. There is waste oil, old fridges, plastic, cardboard, construction waste, old tyres and rubbish being burned on the beach'.

At the same time as these highly visible issues of waste management were taking place, unknown to visiting tourists, a conflict concerning the future development of the island was also being played out. The importance of visitors to Maafushi receiving the tropical paradisal experience during their stay is widely recognised by guesthouse managers. However, Maafushi's finest asset, the northern beach, had been washing away at a rapid rate following the alteration of prevailing sea currents following the construction of a harbour on the western side of the island in 2009. Moreover, a nearby sandbank which was popular with tourists for daytrips had also disappeared. In spite of these drawbacks, many residents on Maafushi were in favour of the harbour due to the economic trade and travel-related benefits that it brought. An Environmental Impact Assessment (EIA) for the harbour development had been completed. However, the White Shell owner, who was most directly affected by the eroding area 
of northern beach, claimed that a double-standard EIA process existed, one high-quality version for resorts, and a second-rate 'botched' version for inhabited islands. Using his computer tablet to pull up a satellite image of the local area, he explained during his interview that:

'You can see the issues when you have a look at the resort island just next to Maafushi, one of the five star resorts. You can see [the five star resort] is picture-perfect isn't it? The beach and everything. But, when you compare that to Maafushi and the harbour, you can see major human intervention in Maafushi. But isn't Maafushi also one of the natural islands of the Maldives? So my argument to the government is, just because Maafushi is a local island, why are you destroying its natural beauty? Why do we need a harbour or a jetty here whereby we are destroying our island?'

Despite the challenges wrought by island-based economic development, guesthouse owners on Maafushi were doing their best to manage and manipulate the island's environment in order to bring it in line with the tourist idyll of long stretches of golden sand and swaying palm trees. For example, in a similar manner to the luxury resorts, they too employed local residents to pick up litter and sweep the northern beach on a daily basis early in the morning before most tourists had risen. There was also a locally-arranged palm tree planting and coral seeding project in operation to improve the aesthetic look of the beach environment. However, producing the tourist imaginary in this area on a longer term basis required major financial input to erect a sea barrier and to dredge sand from the seabed onto the shoreline, resources that the guesthouse owners, unlike the resorts, did not possess. One guesthouse owner explained that he had tried to get money from the Maldivian government to pay for the work but that none had been forthcoming, in spite of the fact that guesthouse owners paid thousands of dollars in tax each year. The owner, who used to be a senior member of the Maldivian government's Ministry of Finance, had even hosted a visit by the Maldives' former president, Mohamed Nasheed in 2012, as well 
as the vice-President of the World Bank for South Asia a year later, during which he put his case forward, but apparently to no avail.

Economic development projects, such as the harbour at Maafushi, potentially represent a harbinger of what is to come for many inhabited islands that are attempting to cultivate a burgeoning guesthouse industry. Government documents show that there are new plans afoot on Maafushi to reclaim land from the sea, effectively doubling the size of the island by the end of 2017. Pressures to undertake these large-scale modifications come from a perceived need to provide houses to an ever-expanding population as well as to attract inward economic investment to the area, as envisaged under the government's plans to create more 'consolidated' population centres across the nation state's territory (Kothari, 2015). However, guesthouse owners strongly oppose island reclamation and population consolidation, fearing negative impacts on their businesses that rely on providing tourists with their 'dream destination'.

Overall, the challenges outlined above illustrate the problems that guesthouse owners face in trying to maintain a pristine version of nature when situated amongst local populations who often have economic priorities that conflict with the plans of tourism managers and investors. Although able to make day-today interventions in order to create an environment 'appropriate' for, and expected by, tourists, many guesthouse owners are unable to keep nature at bay over the longer term due to a lack of financial resources. Moreover, although less reliant upon maintaining an image of remoteness in comparison to resorts due to the differing priorities of lower-paying guests, the economic and housing needs of local populations still intrude upon guesthouse owner's operations in deleterious ways via major infrastructure developments elsewhere.

\section{Conclusion}


As stated at the outset of this article, the relationship between the highly lucrative global tourist industry, local populations and the natural environments that support them has long been subject to the attention of scholarly research, extensive national and international policymaking efforts, strategies of the tourist industry, and the campaigns of social and environmental activists. This article has examined how this relationship is being played out in the context of a particular site, the Maldives, which has long-relied on a specific island imaginary to market itself as a tourist destination, but which is also facing a series of socioeconomic and environmental challenges. Through the exploration of two case studies - the first of a high-end luxury resort positioned on an 'isolated' island and the second of a lower-end guesthouse located on an inhabited island - it has illustrated the kinds of conflicts that can occur when differing understandings of, and priorities for, the 'natural' environment come into contact with one another.

In the Maldives, as in other areas of the world, tourist industries have begun to respond to calls by governments, local communities and tourists themselves to mitigate the adverse effects of the sector on the natural environment through the implementation of sustainable tourism initiatives (Scheyvens 2012). Many of these initiatives take place within a 'weak' sustainability framework in which high-end resorts need to be 'seen to be green' in order to promote their products to high paying tourists and differentiate their offerings from those of their business rivals. However, as this article has shown, rather than preventing further destruction of the natural world, or somehow allowing its natural processes and patterns to occur, the tourist sector can actively seek to alter and manage local environments so as to ensure their continuing attractiveness to high-paying tourists looking for unpeopled, idyllic destinations, often in ways that provoke conflict with the activities and priorities of nearby resident populations. Indeed, consumers' idealised expectations are fuelled and fostered by the careful management of land and sea to provide an illusion of virgin territory and a primeval paradise onto which tourists can map their identities, often invoking particular spatial discourses and practices based on templates from, and 
reminiscent of, the colonial era in the process. This finding runs counter to the belief that tourism industries have become a considerably more benign influence on local environments following the emergence of the sustainable tourism paradigm.

There is currently considerable emphasis in the geographical imaginary literature on the management of the natural environment and how nature can keep 'coming back' if these interventions cease or diminish. This interest arguably reflects a wider, public, post-apocalyptic imaginary of nature 'on the rampage' and acting to reclaim civilisation after human dominance of the natural world has ended, as has been popularised in well-known films such as I Am Legend and books such as the novel The Drowned World by JG Ballard. This article acknowledges the importance of this theme, but also aims to bring people back into the centre of the story in two main ways. First, the article shows how the intensive, meticulous management of local environments, in addition to acting as a critique of the sustainable development discourse, can have real material consequence for people. This was particularly evident in the case of the Kandooma resort, which was able to geographically exclude itself from the local population through major alteration of the local landscape.

Second, the article demonstrates the ways in which local populations can 'push back' at, and disrupt, attempts by tourism managers to create and maintain a pristine, unpeopled environment for tourists. In the first case study, faced by the overwhelming economic resources of the resort, Guraidhoo's population engaged in a form of 'everyday' resistance (Kerkvliet, 2009) in a manner similar to that described in Scott's (1985) well-known book Weapons of the Weak via, for example, throwing rubbish into the sea. In contrast, in the second case study, the long-term viability of the relatively poorlyresourced guesthouse industry on Maafushi was threatened by the needs and demands of the local population, which was greater in number, more politically powerful, and in much closer vicinity. Factors such as these are likely to place considerable pressure on the guesthouse model of tourism 
development in the Maldives in years ahead. Taken together, these findings suggest that the 'people' element requires greater emphasis in the tourist imaginaries literature, particularly as tourism managers strive to create idyllic landscapes in social contexts that are inhabited by local populations with different interests, needs and access to resources.

As argued above, the current prevailing tourist imaginary of pristine, unpeopled, deserted islands presents challenges to the sustainability approach of tourist industries. Furthermore, as discussed, conflicts arise between tourist managers and local populations, and are manifest variously with differential forms of agency exercised by local populations. However, it is not the intention here to deny the agency of tourists. Tourism creates and maintains a particular 'natural' environment that is assumed to reflect the tourist imaginary. However, the act of managing the environment often neglects the role that tourists play in the production of diverse and sometimes contradictory experiences and places. For example, tourists themselves are becoming more discerning with many travelling from countries that advocate addressing climate change while others query how the Maldives can maintain its tourist sector given current environmental challenges. Growing environmental awareness amongst tourists produces a range of complexities and ambiguities that can thwart any easy and simple response by tourism managers through manipulation the local environment.

Moreover, it is important to acknowledge the potential for the growing diversity of tourists to shift the dominance of the specific tropical island imaginary discussed above based as it is on a particular Western and colonial aesthetic. An interviewee from the Ministry of Economic Opportunity commented that the Maldives is now a well-known brand to tourists but the country needs to revive its arts and crafts as there are new kinds of tourists arriving from Russia, China and the Middle East who are less attracted by a pristine beach holiday and more interested in local culture and purchasing products. Such developments have the potential to decentre the values, practices and desires of the Western 
tourist that have for so long preoccupied the mainstream tourism literature. Furthermore, as Sheller (2004) argues, clichéd images of sea, sun, sand and swaying palms have created a situation in which 'a more generic, global and empty signifier of the tropical island could hardly be imagined' (p.26). Thus the potential for a shifting imaginary may enable not only less manipulation of nature and people but also greater recognition of the enormous cultural, historical and environmental diversity of such islands in the first place.

\section{References}

Azcárate MC (2010) Contentious Hotspots: Ecotourism and the Restructuring of Place at the Biosphere Reserve Ria Celestun (Yucatan, Mexico). Tourist Studies 10(2): 99-116.

Bailey C, White, C and R Plain (1999) Evaluating qualitative research: dealing with the tension between 'science' and 'creativity'. Area 31(2): 169-183.

Baldacchino G (2007) Islands as Novelty Sites. Geographical Review 97: 165-174.

Briassoulis $\mathrm{H}$ (2002) Sustainable tourism and the question of the commons. Annals of Tourism Research 29(4): 1065-1085.

Calgaro E and K Lloyd (2008) Sun, sea, sand and tsunami: examining disaster vulnerability in the tourism community of Khao Lak, Thailand. Singapore Journal of Tropical Geography 29: 288-306.

Calgaro E et al. (2014) From vulnerability to transformation: A framework for assessing the vulnerability and resilience of tourism destinations. Journal of Sustainable Tourism 22(3): 341-360. 
Carrigan A (2010) Postcolonial Tourism, Island Specificity, and Literary Representation: Observations on Derek Walcott's Omeros. Space and Culture 13(2): 154-163.

Castree N 2001 Commodity fetishism, geographical imaginations and imaginative geographies.

Environment and Planning A 33(9): 1519-1525.

Cohen E and Cohen SA (2012) Current sociological theories and issues in tourism. Annals of Tourism Research 39(4): 2177-2202.

Cronon W (1996) 'The Trouble with Wilderness; or, Getting Back to the Wrong Nature' in

W. Cronon (ed.) Uncommon Ground: Rethinking the Human Place in Nature. New York: W.W. Norton \& Company, pp. 69-90.

DeLoughrey E (2007) Routes and Roots: Navigating Caribbean and Pacific Island Literatures, Honolulu HI, University of Hawaii Press.

Edensor T (2001) Performing tourism, staging tourism. Tourist Studies 1(1): 59-81

Edensor T and Kothari U (2003) Sweetening Colonialism: A Mauritian Themed Resort. In Lasansky M and McClaren B (eds) Architecture and Tourism. Oxford: Berg

Edensor T (2016) Incipient ruination and the precarity of buildings: materiality, non-human and human agents, and maintenance and repair. In Bille M and Sorensen T (eds) Assembling Architecture. Archaeology, Affect and the Performance of Building Spaces. London: Routledge 
Esparon M, Stoeckl N, Farr M and Larson S (2015) The significance of environmental values for destination competitiveness and sustainable tourism strategy making: insights from Australia's Great Barrier Reef World Heritage Area. Journal of Sustainable Tourism 23(5): 706-725.

Farrell BH and Runyan D (1991) Ecology and Tourism. Annals of Tourism Research 18: 26-40.

Farrel BH and Twining-Ward L (2004) Reconceptualising tourism. Annals of Tourism Research 31(2): 274-295

Gordon, Avery (1997) Ghostly Matters. Minneapolis: Minnesota University Press

Goudie AS (2013) The Human Impact on the Natural Environment: Past, Present, and Future. Oxford, England: Wiley-Blackwell

Graham S and Thrift N (2007) Out of order: understanding repair and maintenance. Theory, Culture \& Society 24(3): 1-25.

Grimwood BSR, Yudina O, Muldoon M and Qiu J (2015) Responsibility in tourism: a discursive analysis. Annals of Tourism Research 50:22-38.

Grove RH (1995) Green Imperialism: Colonial Expansion, Tropical Island Edens and the Origins of Environmentalism, 1600-1860. Cambridge, England: Cambridge University Press. 
Hennessy E and McCleary AL (2011) Nature's Eden? The Production and Effects of 'Pristine' Nature in the Galapagos Islands. Island Studies Journal 6(2): 131-156.

Hillery M, Nancarrow B, Griffin G and Syme G (2001) Tourist perception of environmental impact. Annals of Tourism Research 28(4):853-867.

Hinchliffe S (2007) Geographies of nature: societies, environments, ecologies. London: Sage.

Holden A (2009) The environment-tourism nexus: influence of market ethics. Annals of tourism research 36(3): 373-389.

Kerkvliet BJT (2009) Everyday politics in peasant societies (and ours). The Journal of Peasant Studies 36(1): 227-243.

Kern R (2000) Ecocriticism: What is it Good For? Interdisciplinary Studies in Literature and Environment 7: 9-32.

Kitchin R and NJ Tate (2000) Conducting research into human geography: theory, methodology and practice. Harlow, Prentice-Hall.

Kothari U (2015) Reworking colonial imaginaries in post-colonial tourist enclaves. Tourist Studies 15(3): 248-266.

Kothari U and Wilkinson R (2010) Colonial Imaginaries: Exiles, Bases, Beaches. Third World Quarterly $31(8): 1395-1412$. 
Kousis M (2000) Tourism and the environment: a social movements perspective. Annals of Tourism Research 27(2): 468-489.

Lynch T (2011) Review of Postcolonial Tourism: Literature, Culture, and Environment by Anthony Carrigan. Postcolonial Text 6(4)

Massey D (2005) For space. London: Sage.

Mbaiwa JE and Stronza AL (2009) Challenges and prospects for sustainable tourism and ecotourism in developing countries. In Jamal T and Robinson M (eds.) The SAGE Handbook of Tourism Studies. London: SAGE Publications. 333-351.

Moranda, S. (2015) The emergence of an environmental history of tourism. Journal of Tourism History 7(3): 268-289.

Ministry of Tourism (2015) Maldives Visitors Survey Report. Report, MoT, Maldives, February.

Ministry of Tourism Arts and Culture (2013) Fourth Tourism Masterplan. Report, MTAC, Maldives, September.

Nunkoo R and Gursoy D (2012) Residents' support for tourism: an identity perspective. Annals of Tourism Research 39(1): 243-268. 
Osagie I and Buzinde CN (2011) Culture and postcolonial resistance Antigua in Kincaid's A Small Place. Annals of Tourism Research 38(1): 210-230.

Saarinen J (2006) Traditions of sustainability in tourism studies. Annals of Tourism Research 33(4): $1121-1140$.

Said E (1979) Orientalism. London: Penguin.

Scott JC (1985) Weapons of the Weak: Everyday Forms of Peasant Resistance. New Haven: Yale University.

Scheyvens R (2012). Tourism and poverty. Routledge.

Sheller M (2004) Natural hedonism: The invention of Caribbean islands as tropical playgrounds. In: Tourism in the Caribbean: Trends, Development, Prospects, ed. D.T. Duval, 23-38. London, UK: Routledge.

Slater C (1996) Amazonia as Edenic Narrative. In Uncommon Ground: Rethinking the Human Place in Nature Cronon W (ed.). New York: W. W. Norton. 119-121

Stratford E, Baldacchino G, McMahon E, Farbotko C and Harwood, A. (2011) Envisioning the archipelago. Island Studies Journal, 6(2): 113-130.

UNDP (2014) Maldives Human Development Report. United Nations Development Programme. Report, Ministry of Finance and Treasury and the United Nations Development Programme in the Maldives, Maldives, June. 
Uyarra MC, Côte IM, Gill JA, Tinch RRT, Viner D and Watkinson AR (2005) Island-specific preferences of tourists for environmental features: implications of climate change for tourism-dependent states. Environmental Conservation 32(1): 11-19.

Whatmore S (2002) Hybrid Geographies. Natures, Cultures and Spaces. London: Sage.

Yang J, Ryan C and Zhang L (2013) Social conflict in communities impacted by tourism. Tourism Management 35: 82-93.

Zubair, S, Bowen, D and Altinay, L (2015) Enclave resort tourism in Maldives: Destination development and resistance to change. In Wilson, E and Witsel, M (Eds) CAUTHE 2015: Rising Tides and Sea Changes: Adaptation and Innovation in Tourism and Hospitality. Gold Coast, QLD: School of Business and Tourism, Southern Cross University, 793-796. 